\title{
Influence of Recrystallization Annealing Modes on the Mechanical Properties of Copper Pipes After Large Plastic Deformation
}

\author{
Maria Shalaeva ${ }^{1,2}$ and Yuri Loginov ${ }^{3,4, *}$ \\ ${ }^{1}$ UMMC, 1 Uspenskiy Ave., Verkhnaya Pyshma, Sverdlovsk Region, 624091, Russian Federation \\ 2 PJSC "Revda non-ferrous metal processing works", 1 Kombinatskaya Str., Revda, Sverdlovsk \\ Region, 623280, Russian Federation \\ ${ }^{3}$ Ural Federal University, 19 Mira Str., Ekaterinburg, 620002, Russian Federation \\ ${ }^{4}$ M.N. Miheev Institute of Metal Physics, Ural Branch of Russian Academy of Sciences, \\ Ekaterinburg, 620002, Russian Federation
}

\begin{abstract}
This paper presents the influence of heat treatment modes on product quality parameters. The experiments were carried out on Cu-DHP pipes at various annealing temperature and time. Grain size and mechanical properties dependence on annealing mode were plotted for phosphoruscontaining copper. Laboratory results were taken into account for setting process parameters and were industrially tested.
\end{abstract}

\section{Previous papers}

To expand sales markets, copper pipe manufacturers are mastering production according to international standards. Grain size and mechanical properties of pipes for refrigeration units and oil pipelines required under these standards are significantly different than those required under Russian specifications. In particular, copper pipes must be made extra-soft with a minimum of time and energy.

Deformation and thermal behavior of copper largely depend on its grade. There is a pretty stark difference between oxygen-free, oxygen-containing and phosphorus-containing copper. In [1] they found that at a logarithmic strain above 5, recrystallization temperature of ETP copper is lower than recrystallization temperature of OF copper, regardless of the time of recrystallization. The authors of [2] investigated the influence of industrial annealing parameters for pipes made of M1r heat-engineering copper.

It has been established that under cumulative cold strain during drawing with $99.4 \%$ percent reduction, vacuum annealing at $500^{\circ} \mathrm{C}$ for 5.5 hours results in a recrystallized state when the grain reaches $9.9 \mu \mathrm{m}$ on average. It was noted in [3] that hot straining of copper does not always results in full annealing. Additional annealing of hot-rolled oxygencontaining copper within $300-700^{\circ} \mathrm{C}$ modifies copper properties. [4] stresses that in $99.97 \%$ pure ETP copper cold-worked to high strain (5.7 logarithmic reduction) recrystallization develops at room temperature. Despite its low rate, after aging for a month, the percentage

* Corresponding author: j.n.loginov@urfu.ru 
of recrystallized grains is fairly high. Therefore, cold-working to high strain lowers the onset temperature of recrystallization down to room temperature. Technical publications state that adding phosphorus to copper will, in particular, increase creep strength. In particular, it was found that the relative elongation at break of copper with added phosphorus under creep at $200^{\circ} \mathrm{C}$ amounted to $40 \%$, while for phosphorus-free copper it was only $10 \%$ [5]. It was also noted that setting final annealing parameters largely affects the texture of both oxygen-bearing [6] and phosphorus-bearing copper [7,8].

Development of new standards for copper products has translated into significantly higher requirements for structural condition and mechanical properties. The purpose of this work is to assess the properties of phosphorus-containing copper pipes under industrial conditions.

\section{Material Attributes}

In our case, we are examining the specifics of manufacturing copper pipes under ASTM B68 standard. The standard applies to bright annealed seamless copper pipes suitable for use in refrigeration, oil and gas pipelines, etc., where tube with a clean interior surface is essentially required (Fig. 1). They can be manufactured using oxygen-free copper or phosphorus-deoxidized copper of various phosphorus content. Particular attention will be paid to C12200 high-residual-phosphorus copper. The standard provides that copper content must be at least $99.9 \%$ and phosphorus content must be within 0.015 and $0.040 \%$. In $\mathrm{O} 60$ condition, the grain size must be at least $40 \mu \mathrm{m}$. Tensile strength must be at least $210 \mathrm{MPa}$ with elongation at break of at least $40 \%$. European standards describe such copper as $\mathrm{Cu}-\mathrm{DHP}$ (phosphorus-deoxidized high-residual phosphorous copper). Its Russian equivalent is M1f copper with a chemical composition according to standard GOST 8592001 .

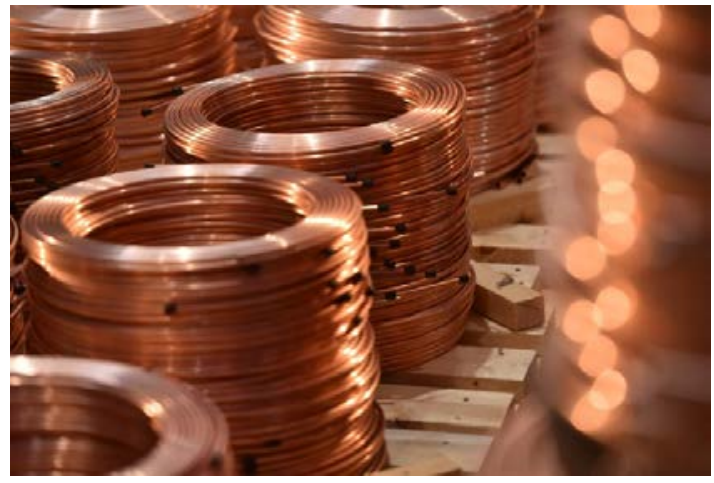

a

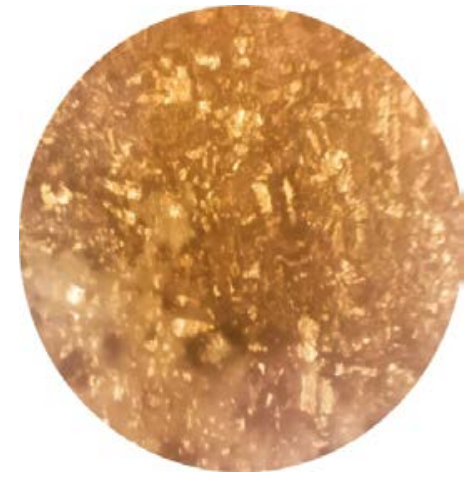

b

Fig. 1. Spiral Wound Copper Pipes as per standard ASTM B68 (a), metal structure (b)

Specification for the minimum allowable grain size value is something out of the ordinary. In most cases, the goal is the quite opposite - to reduce grain size in one way or another to achieve the grain boundary strengthening effect. It should be noted that the grain size in copper has its optimum value. For example, under reference documents, the optimal grain size for copper is $35 \mu \mathrm{m}$; at a lower value, plasticity decreases, and at a higher value, the surface finish of the product deteriorates due to inhomogeneous deformation of the grains, which reduces, for example, pipe capacity [9]. This explains why standard ASTM B68 limits grain size to $40 \mu \mathrm{m}$.

The existing pipe heat treatment modes are designed to meet the requirements of standard GOST 617-2006, which does not provide for grain size. Statistical analysis 
revealed that $95 \%$ of as-annealed pipes produced have a grain size of 20-35 $\mu \mathrm{m}$ under standard heat treatment, which corresponds to O50 state (bright annealing) according to standard ASTM B68 and fails to meet the required O60 state (soft annealing).

\section{Description of the method used}

Under standard recrystallization annealing, hold time is 40 minutes at $560^{\circ} \mathrm{C}$, charge heating and cooling, as well as furnace evacuation is 80 minutes. Repeated heat treatment and longer hold times reduce plant section performance and result in finishing operation downtime. In production, heat treatment is carried out in an Otto Junker furnace for bright annealing with a protective atmosphere in the form of a nitrogen-hydrogen mixture (Fig. 2).

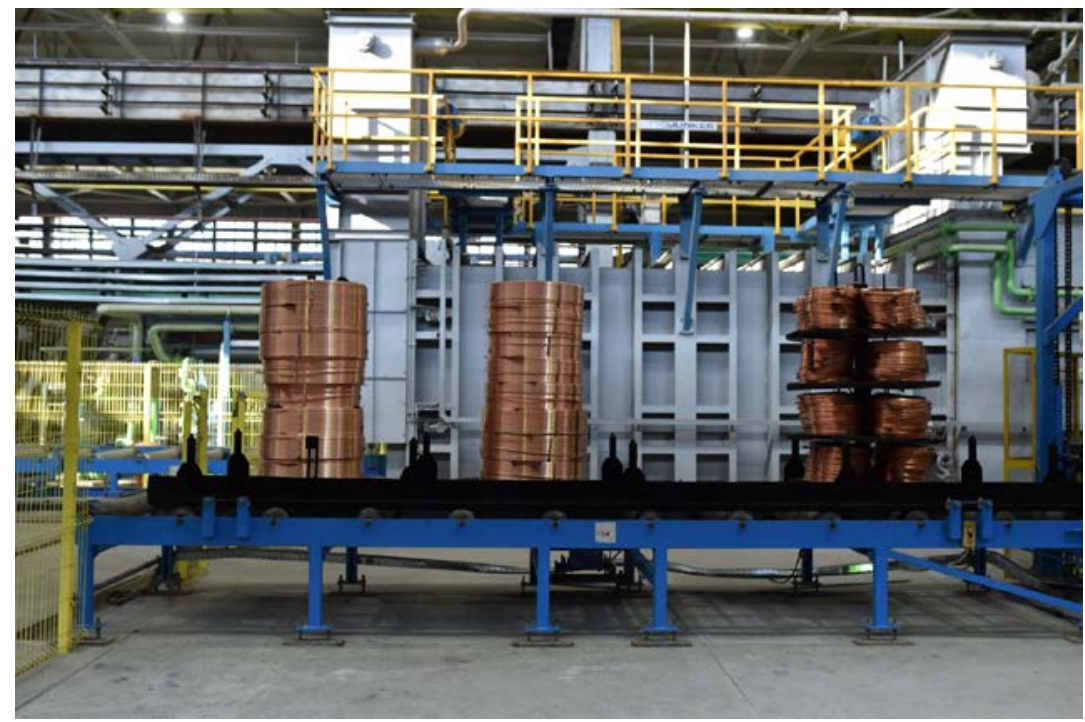

Fig. 2. Copper pipes for refrigerating appliances being unloaded from the Otto Junker furnace for bright annealing

Initially, the experiment was carried out in a PVL K-318 laboratory resistance furnace on 6x1 mm drawn Cu-DHP copper pipes. The strain (logarithmic deformation) is 4.5. Two parameters were changed during the experiment: annealing temperature and time.

Rational parameters identified by laboratory studies were then tested by annealing in an Otto Junker industrial furnace.

\section{Laboratory and industrial experiment results}

After annealing in a laboratory furnace under different heat treatment modes, samples were taken to measure the grain size, as well as the tensile strength and elongation at break.

Measurement values are summarized in Table 1 and shown in graphs (Fig. 3-5). 
Table 1. Grain size and mechanical properties of copper pipes after different annealing modes

\begin{tabular}{|c|c|c|c|c|c|}
\hline $\begin{array}{c}\text { Experiment } \\
\text { number }\end{array}$ & $\begin{array}{c}\text { Annealing } \\
\text { temperature, }{ }^{\circ} \mathrm{C}\end{array}$ & $\begin{array}{c}\text { Annealing (hold) } \\
\text { time, min }\end{array}$ & $\begin{array}{c}\text { Average } \\
\text { grain } \\
\text { size, } \mu \mathrm{m}\end{array}$ & T.S., MPa & $\begin{array}{c}\text { Elongation at } \\
\text { break, } \%\end{array}$ \\
\hline 1 & 550 & 40 & 20 & 258 & 50 \\
\hline 2 & 575 & 40 & 20 & 261 & 50 \\
\hline 3 & 575 & 80 & 30 & 256 & 44 \\
\hline 4 & 600 & 40 & 30 & 251 & 52 \\
\hline 5 & 600 & 80 & 40 & 246 & 50 \\
\hline 6 & 625 & 40 & 40 & 245 & 50 \\
\hline 7 & 625 & 80 & 27 & 250 & 48 \\
\hline 8 & 650 & 40 & 40 & 238 & 48 \\
\hline
\end{tabular}

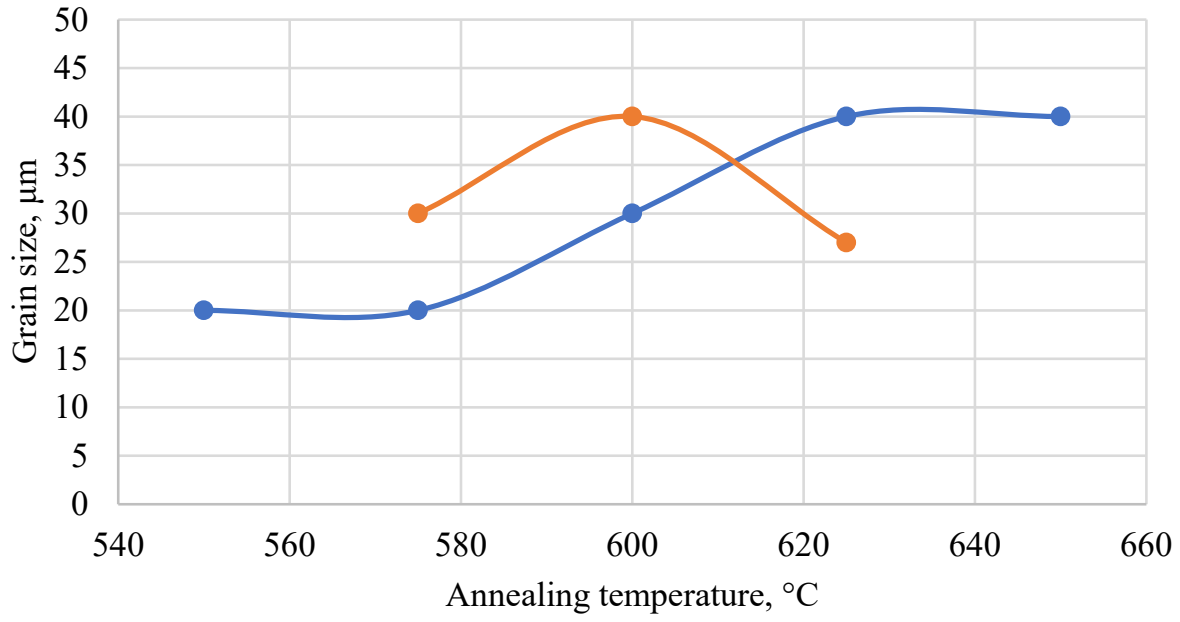

Annealing time: 40 minutes

Annealing time: 80 minutes

Fig. 3. Grain size-copper pipe annealing time and temperature curve

The average grain size (Fig. 3) ranges from 20 to $40 \mu \mathrm{m}$. That said, it was found that a smaller grain size in the range of 20 to $30 \mu \mathrm{m}$ is achieved at the annealing time of $40 \mathrm{~min}$ and a reduced temperature in the range of 550 to $600^{\circ} \mathrm{C}$. A further increase in temperature results in an increase in grain size up to $40 \mu \mathrm{m}$. This is compliant with the laws established in metal science $[10,11]$. An increase in annealing time to 80 min revealed that there was a local maximum at a temperature of $600^{\circ} \mathrm{C}$. 


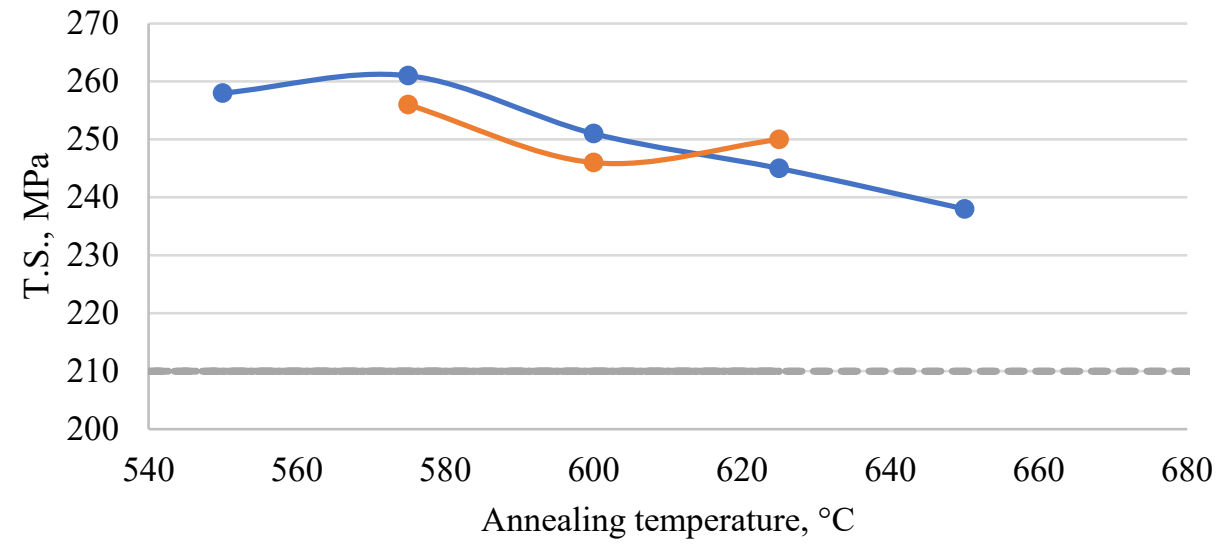

$\longrightarrow$ Annealing time: 40 minutes $\longrightarrow$ Annealing time: 80 minutes $-\infty$ Minimum allowable value

Fig. 4. Tensile strength-copper pipe annealing time and temperature curve

At the annealing time of 40 min tensile strength (Figure 4) looks down from $260 \mathrm{MPa}$ to $240 \mathrm{MPa}$, which can be explained by an increasing degree of recrystallization. Annealing for $80 \mathrm{~min}$ in a shorter temperature range repeats the results of shorter-time annealing. The graph shows that measurement values are above the limit value, which comes up to the standard.
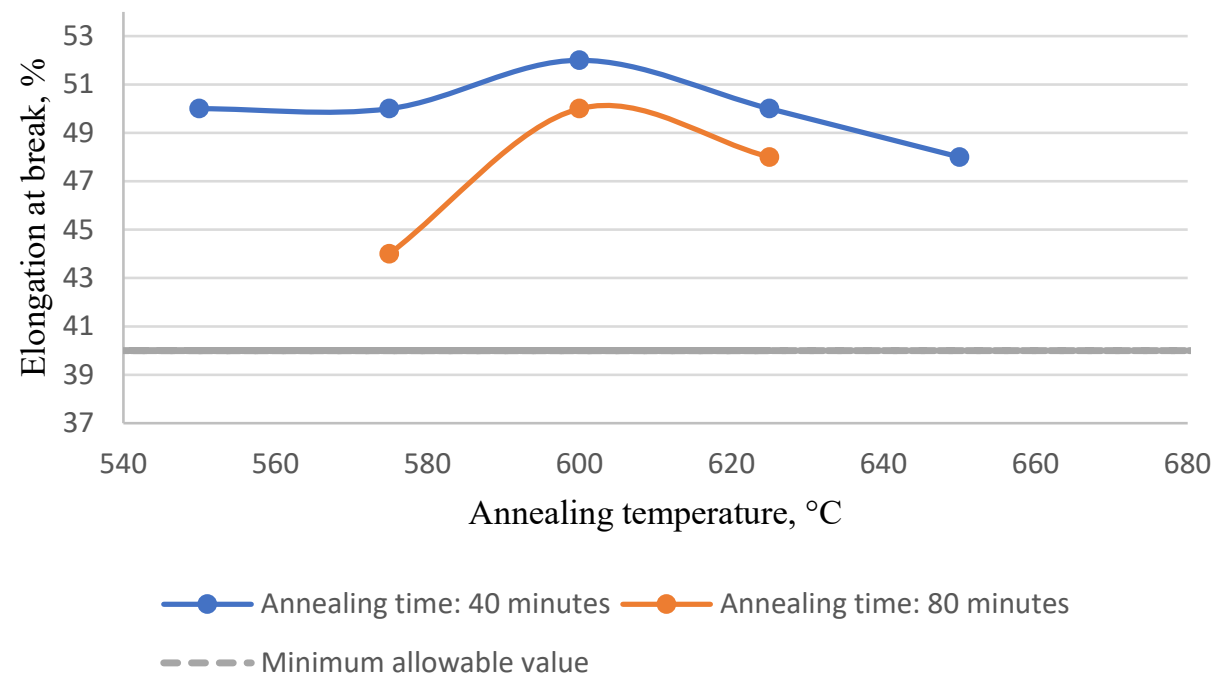

Fig. 5. Elongation at break - copper pipe annealing time and temperature curve

Elongation at break to fracture (Figure 5) peaks at an annealing temperature of $600^{\circ} \mathrm{C}$, and that is typical for both shorter and longer annealing times.

The experiment demonstrated that the required grain size of $40 \mu \mathrm{m}$ was consistently achieved in the $625-650^{\circ} \mathrm{C}$ temperature range with a hold time of $40 \mathrm{~min}$. Double annealing 
time yielded the desired grain at a lower temperature $-600^{\circ} \mathrm{C}$.However, at a slight increase in temperature - by $25^{\circ} \mathrm{C}$ - softening appears, and grain size decreases.

Tensile strength does not take a value less than the limit value in any experiment, but it should be taken into account that, all other things being equal, the maximum tensile strength is given priority when choosing heat treatment mode. This measure is necessary to minimize the risk of dents and other mechanical damage when transporting soft pipes at manufacturing site and upon delivery to customer.

In view of experiment results, priority was given to a 40 -minute holding at $625^{\circ} \mathrm{C}$. With due regard to the differences between the laboratory and industrial furnace, heat treatment mode on the shop floor was set at $630 \ldots 655^{\circ} \mathrm{C}$ for 120 minutes. Thus, the time under the standard industrial mode was not increased. The industrial experiment produced positive results: we achieved the required grain size of $40 \mu \mathrm{m}$ and mechanical properties complying with standard ASTM B68 (240-250 MPa tensile strength, 45-50\% elongation at break).

\section{Conclusion}

Grain size and mechanical properties dependence on annealing mode were plotted for phosphorus-containing copper. The results were industrially tested. Suggested heat treatment modes allowed for manufacturing products that comply with international standards without loss of performance of the existing equipment.

\section{References}

1. M. Zasadzińska, T. Knych, P. Strzępek, B. Jurkiewicz. K. Franczak, Analysis of the strengthening and recrystallization of electrolytic copper (Cu-ETP) and oxygen free copper (Cu-OF), Arch. of Civil and Mech. Eng, v. 19, pp. 186-193, (2019)

2. Yu. Loginov, S.L. Demakov, A.G. Illarionov, M.A. Ivanova, M.S. Shalaeva, Comparison of heat engineering copper structures in high cold worked and recrystallized conditions, Tsvetnye Metally, v.8, pp. 92-96, (2013)

3. Y.N. Loginov, S.L. Demakov, M.A. Ivanova, A.G. Illarionov, M.S. Karabanalov, S.I. Stepatov, Effect of annealing on properties of hot-rolled electrical copper, Ph. of Met. and Metallogr, v. 116(4), pp. 393-400, (2015)

4. J.Schamp, B.Verlinden, J. Van, Humbeeck Recrystallisation at ambient temperature of heavily deformed ETP copper wire, Scr. Mat., v. 34(11), pp. 1667-1672, (1996)

5. K. Pettersson, A study of grain boundary sliding in copper with and without an addition of phosphorus, J. Nucl. Mat, v. 405(2), pp. 131-137, (2010)

6. M.A. Zorina, M.S. Karabanalov, Y.N. Loginov, Surface texture of deformed copper wire, IOP Conf. Series: Mat. Sc. and Eng., v.969(1), (2020)

7. Y.N. Loginov, M.S. Shalaeva, S.L. Demakov, M.A. Ivanova, A.G. Illarionov, Severe deformation, structure, and texture of the metal in the production of capillary copper pipes, Rus. Metal., v. 5, pp. 372-376, (2014)

8. S. Taylor, I. Masters, Z. Li, H. R. Kotadia, Direct observation via in situ heated stage EBSD analysis of recrystallization of phosphorous deoxidised copper in unstrained and strained conditions, Met.and Mater. Int., v. 26, pp. 1030-1035, (2020)

9. M.S. Shalaeva, Y.N. Loginov, Flow capacity of the capillary copper tube as its figure of merit, IOP Conf. Ser.: Mat. Sc. and Eng., v. 971(2), (2020)

10. A. A. Ridha, W.B. Hutchinson, Recrystallisation mechanisms and the origin of cube texture in copper, Act. Met., v. 30(10), pp. 1929-1939, (1982)

11. E. Lindh, B. Hutchinson, S. Ueyama, Effect of redundant deformation on recrystallisation behaviour of copper, Scr. Met. et Mat., v. 29(3), pp. 347-352, (1993) 